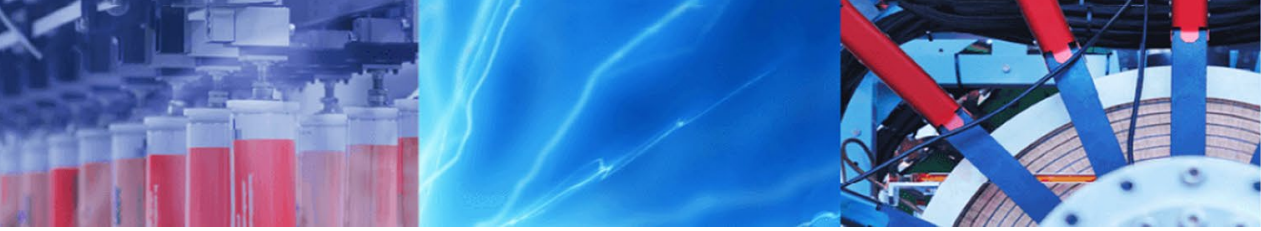

Research Article

\title{
Simultaneous electrochemical investigations of dopamine and uric acid by in situ amino functionalized reduced grahene oxide
}

\author{
Anita K. Tawade ${ }^{1}$ - Bhagyashri B. Kamble ${ }^{2} \cdot$ Kiran Kumar K. Sharma $^{1} \cdot$ Shivaji N. Tayade $^{3}$ (D)
}

Received: 18 February 2020 / Accepted: 22 April 2020 / Published online: 15 May 2020

(c) Springer Nature Switzerland AG 2020

\begin{abstract}
We have synthesized amino functionalized reduced graphene oxide $\left(\mathrm{NH}_{2}-\mathrm{rGO}\right)$ composite. Bucherer reaction was used for the in situ modification of graphene oxide into the $\left(\mathrm{NH}_{2}-\mathrm{rGO}\right)$. A simple hydrothermal method was utilized for proposed synthesis. Electrochemical sensor was fabricated by drop coating $\mathrm{NH}_{2}-\mathrm{rGO}$ nanocomposite onto the glassy carbon electrode (GCE) for individual and the simultaneous detection of dopamine (DA) and uric acid (UA). The $\mathrm{NH}_{2}$-rGO materials formation was confirmed by X-ray diffraction, IR, UV and FE-SEM. The electrochemical sensing of DA and UA was examined by cyclic voltammetry and differential pulse voltammetry. For individual detection of DA, the linear responses of current concentration plot was found in the concentration range of $2.04 \times 10^{-4}-2.04 \times 10^{-3} \mathrm{M}$ with detection limit $1.4 \times 10^{-4} \mathrm{M}$ $(\mathrm{S} / \mathrm{N}=3)$ and for $\mathrm{UA}, 1.8 \times 10^{-3}-1.8 \times 10^{-4} \mathrm{M}$ with detection limit $1.67 \times 10^{-4} \mathrm{M}(\mathrm{S} / \mathrm{N}=3)$. The $\mathrm{NH}_{2}-\mathrm{rGO} / \mathrm{GCE}$ electrochemical sensor further tested for the simultaneous detection of binary mixtures of DA and UA and found to be high sensitive compared to individual detection of DA and $\mathrm{UA}$ at $\mathrm{pH}$. Sensor selectivity is demonstrated in the presence of $2 \times 10^{-4} \mathrm{M}$ concentrations of potentially active interfering compounds including dopamine, uric acid and glucose isomers.
\end{abstract}

Keywords Uric acid · Dopamine $\cdot$ Hydrothermal reaction $\cdot$ Reduced graphene oxide $\cdot$ Bucherer reaction

\section{Introduction}

Dopamine (DA) acts as an important neurotransmitter in physiological systems of human brain and neural system [1]. The DA hydrochloride salt is used for the shock treatment in the heart attack, open heart surgery and bacterial infectious diseases. The increase in the level of DA concentration in the biological systems of human body causes several diseases such as Schizophrenia, Huntington and Parkinson disease [2-4]. Hence, the selective and sensitive detection of DA is essential.

UA also plays an important role in purines digestion system. It acts as one of the essential circulating low molecular weight antioxidants [5]. Normal UA level in urine and blood is generally ranges between $1.49-4.46 \mathrm{mM}$ and
120-450 mM respectively [6]. Abnormal amounts of UA may causes diseases such as gout, hyperuricemias and Lesch-Nyhamsyndrome, leukemia and pneumonia [7]. Therefore, the improvement of sensitive, fast and selective methods for the measurement of DA and UA in the biological system is essential.

Various techniques has been explored to detect DA and UA via electrophoresis, fluorometry [8] chromatography [9] chemiluminsence [10] spectrophotometry [11] etc. but the main drawbacks of these techniques are operational conditions and required experimental equipment. Therefore, an electrochemical analysis has been on increasing demand by many researchers due to its simplicity, reproducibility and selectivity [12]. On the other hand DA and UA are co-existing therefore; it is highly enviable to

$\triangle$ Shivaji N. Tayade, snt_chem@unishivaji.ac.in | 'School of Nanoscience and Technology, Shivaji University, Kolhapur, Maharashtra 416004, India. ${ }^{2}$ Shivraj College Gadhinglaj, Shivaji University, Kolhapur, Maharashtra 416004, India. ${ }^{3}$ Department of Chemistry, Shivaji University, Kolhapur, Maharashtra 416004, India. 
detect DA and UA simultaneously. Thus, an electrochemical investigations with a slight modification of materials must be developed, which shows a complete resolution of electrochemical signals for a molecules of interest even in the presence of an active interfering molecules. Recently, materials with the excellent electro-catalytic activities, like graphene oxide [13] carbon nanotubes [14] metal nanoparticles [15] metal oxide [16] and conducting polymers $[15,17]$ carbon paste electrode $[18,19]$ have been explored as electrode modifiers for simultaneous detection of biomolecules. Graphene is extensively studied material due to its extraordinary properties like high surface area, conductivity and high chemical stability. Various methods and facile routes to synthesis of reduced $\mathrm{GO}$ namely chemical reduction [20] electrochemical reduction [21] and thermal reduction [22] are frequently adopted for high yields, purity and its application [23-25]. Hans Th. Bucherer invented the reaction of nucleophilic substitution of amine $\left(-\mathrm{NH}_{2}\right)$ to aromatic phenols particularly naphthol with ammonia in the presence of sodium bisulfate [26]. We have slightly modified this reaction for in situ transformation of $\mathrm{GO}$ into $\left(-\mathrm{NH}_{2}\right)$ substituted $\mathrm{rGO}$. The substitution of $\mathrm{NH}_{2}$ groups in $\mathrm{rGO}$ enhances the ability of interactions of $\mathrm{NH}_{2}-\mathrm{rGO}$ with the molecules to be detected as can be seen in case of energy storage devices like (battery, supercapacitor, Fuel cell, etc.) [27] electrocatalytic oxygen reduction reactions (ORR) [28], electrochemical sensors (Biomolecules sensing, drug sensing, pesticide sensing, etc.) $[29,30]$ solid basic catalyst in organic chemistry [31] and optical graphene quantum dots [32, 33]. Amine functionalization in carbaneous materials has been used to enhance the controlled covalent bonding to a polymers or biological molecules [34].

In this work a simple drop coat method is utilized for the fabrication of amino r-GO modified glassy carbon electrode (GCE). The prepared modified electrode presented an excellent electro catalytic activity for electrochemical oxidation of DA due to the high surface area and enhanced electrical conductivity of amino r-GO. Moreover, the amino $\mathrm{r}$-GO/GCE modified electrode shows excellent sensitivity and selectivity towards the detection of DA and UA simultaneously.

\section{Methodology}

Graphite flakes, Sulphuric acid (99\% AR), Phosphoric acid (AR $88 \%)$, Potassium permagnate $\left(\mathrm{KMnO}_{4}\right)(\mathrm{AR})$. ACS, Dimethyl sulphoxide (DMSO) (99\% AR), Hydrochloric acid (98\% AR), Hydrogen peroxide $\left(\mathrm{H}_{2} \mathrm{O}_{2}\right)$ were purchased from Sigma Aldrich. Sodium bisulfate $\left(\mathrm{NaHSO}_{3}\right)$, Ammonia $\left(\mathrm{NH}_{3}\right)$ (97\%).

\subsection{Preparation of $\mathrm{NH}_{2}-\mathrm{rGO}$ composite by using Buchner reaction}

GO was synthesized by the improved Hummers method [35]. This was further reduced and functionalized with $\left(-\mathrm{NH}_{2}\right)$ in one step synthesis in an autoclave. In a typical synthesis, $28.57 \mathrm{mg}$ of $\mathrm{GO}$ was dispersed in $40 \mathrm{~mL}$ water in an autoclave tube $28.57 \mathrm{mmol} \mathrm{NH}_{3}$ and $5.7 \mathrm{mmol}$ sodium bisulfate $\left(\mathrm{NaHSO}_{3}\right)$ were into the dispersed $\mathrm{GO}$. Autoclave was kept in oven at $170^{\circ} \mathrm{C}$ for $10 \mathrm{~h}$. After cooling to ambient temperature, the resulting material was washed by centrifugation and re-dispersion in triple distilled water 3 times to remove $\mathrm{NaHSO}_{3}$ catalyst and non-reacted ammonia. The prepared amino-rGO is dried in vacuum oven at $60^{\circ} \mathrm{C}$ and redispersed in water as well as organic solvents such as ethanol and dimethyl formamide for desired applications.

\subsection{Apparatus}

The powder X-ray diffraction (XRD) analysis was recorded using a Bruker D8 advance X-ray diffractometer (XRD) rotating anode $\mathrm{X}$-ray generator working at $\mathrm{Cu}-\mathrm{Ka}$ monochromatic radiation $(\lambda=1.5418 \AA$ ) . The field emission scanning electron microscopy (FE-SEM) observation was performed with Hitachi SU-70 (Japan). Fourier transform infrared (FTIR) spectroscopy analysis was performed using FTIR-6600 spectrometer (Bruker Company), spectrum were taken with $\mathrm{KBr}$, and recorded on an IFS $66 \mathrm{~V} / \mathrm{S}$. The UV-visible spectrum was recorded by a CARY Bio 100 spectrophotometer. The redox behavior of DA was performed by cyclic voltammetry (CV) and differential pulse voltammetry (DPV) using electrochemical workstation PGATAT302N (Metrohm Auotolab). A conventional threeelectrode system is used for the redox investigations of DA and UA. The system consists the modified GCE as a working electrode (geometric area $=0.07 \mathrm{~cm}^{2}$ ), platinum wire as a counter electrode and $\mathrm{Ag} / \mathrm{AgCl} 3 \mathrm{M} \mathrm{KCl}$ as a reference electrode. Figure 1 represents the graphical abstract for $\mathrm{NH}_{2}$-rGO modified electrode and the corresponding oxidation mechanism of DA and UA.

\section{Result and discussion}

The XRD pattern shown in Fig. 2a represents the sharp diffraction peak at $10^{\circ}$ indicates (001) plane of the pristine $G O$ in agreement with literature [36]. Figure $2 b$ depicts XRD pattern of amino functionalized $\mathrm{rGO}$ in which the layer-tolayer distance of $0.83 \mathrm{~nm}$ in $\mathrm{GO}$ is calculated using Bragg's equation. The broad diffraction peak at around $29.85^{\circ}$ 


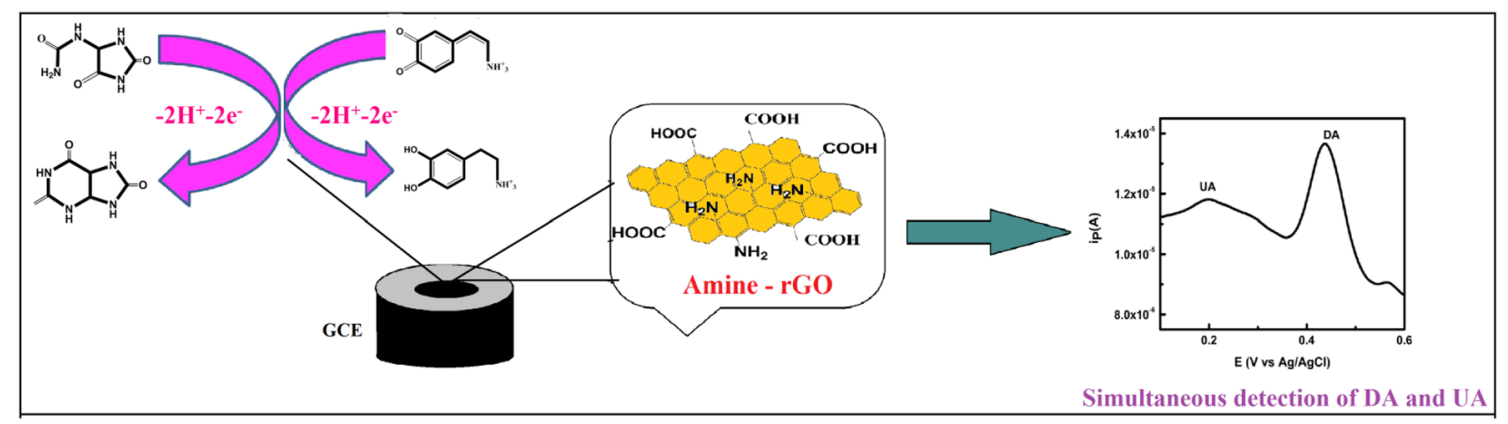

Fig. 1 Schematics represents synthesis of amine functionalized-rGO composites

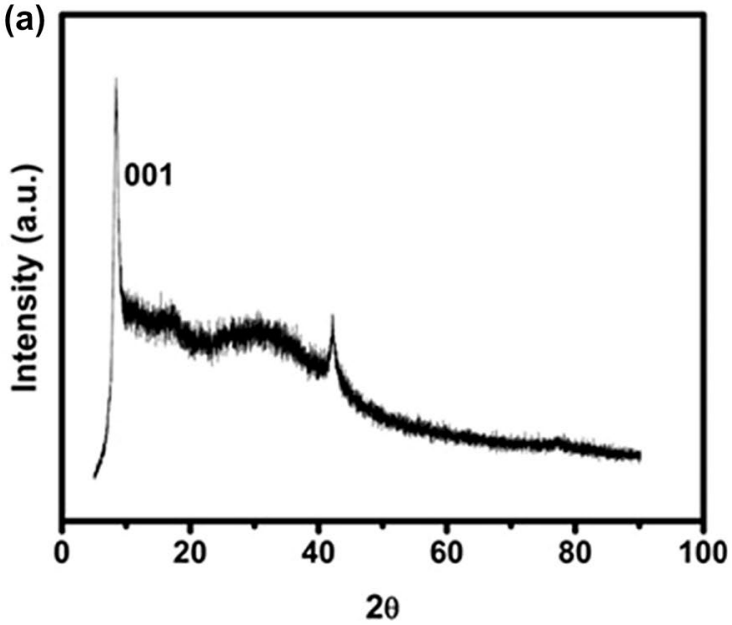

Fig. 2 XRD spectra of synthesized a graphene oxide, $\mathbf{b}$ amino-rGO

with d-spacing of $12.59 \mathrm{~nm}$ is attributed to the disordered stacking structures of amino-rGO layers. The increase in the layer-to-layer distance in $\mathrm{NH}_{2}-\mathrm{rGO}$ signifies the fact that $-\mathrm{NH}_{2}$ groups covalently attached to the $\mathrm{rGO}$ surface. The commonly aggregated $\mathrm{GO}$ sheets are efficiently exfoliated to basal sheets which are coupled with amine groups [33], this structure reveals the transformation from a crystalline state to the amorphous state.

Figure 3 depicts FTIR spectra of $\mathrm{GO}$ and $\mathrm{NH}_{2}$-rGO. A broad peak at $3400 \mathrm{~cm}^{-1}$ attributed to the stretching of $\mathrm{O}-\mathrm{H}$ groups of adsorbed water, alcohol and carboxylic acid [37]. The sharp peak at $1741 \mathrm{~cm}^{-1}$ is ascribed to the $C=O$ stretching of carboxylic acid group, $1646 \mathrm{~cm}^{-1}$ to the $s p^{2}(\mathrm{C}=\mathrm{C})$ and conjugated $\mathrm{C}=\mathrm{O}$ stretching. For $\mathrm{NH}_{2}-\mathrm{rGO}$, a sharp peak $3366 \mathrm{~cm}^{-1}$ attributed to $\mathrm{N}-\mathrm{H}$ stretching. Compared to $\mathrm{GO}$, in $\mathrm{NH}_{2}-\mathrm{rGO}$ the absorption bands in the frequency range of $3500-2500 \mathrm{~cm}^{-1}$ are remarkably decreased attributed to the reduction of oxygen functional groups confirms the reduction of $\mathrm{GO}$ into $\mathrm{rGO}$ with a substituted amino groups. Other outstanding differences are observed in the appearance of the two peaks at
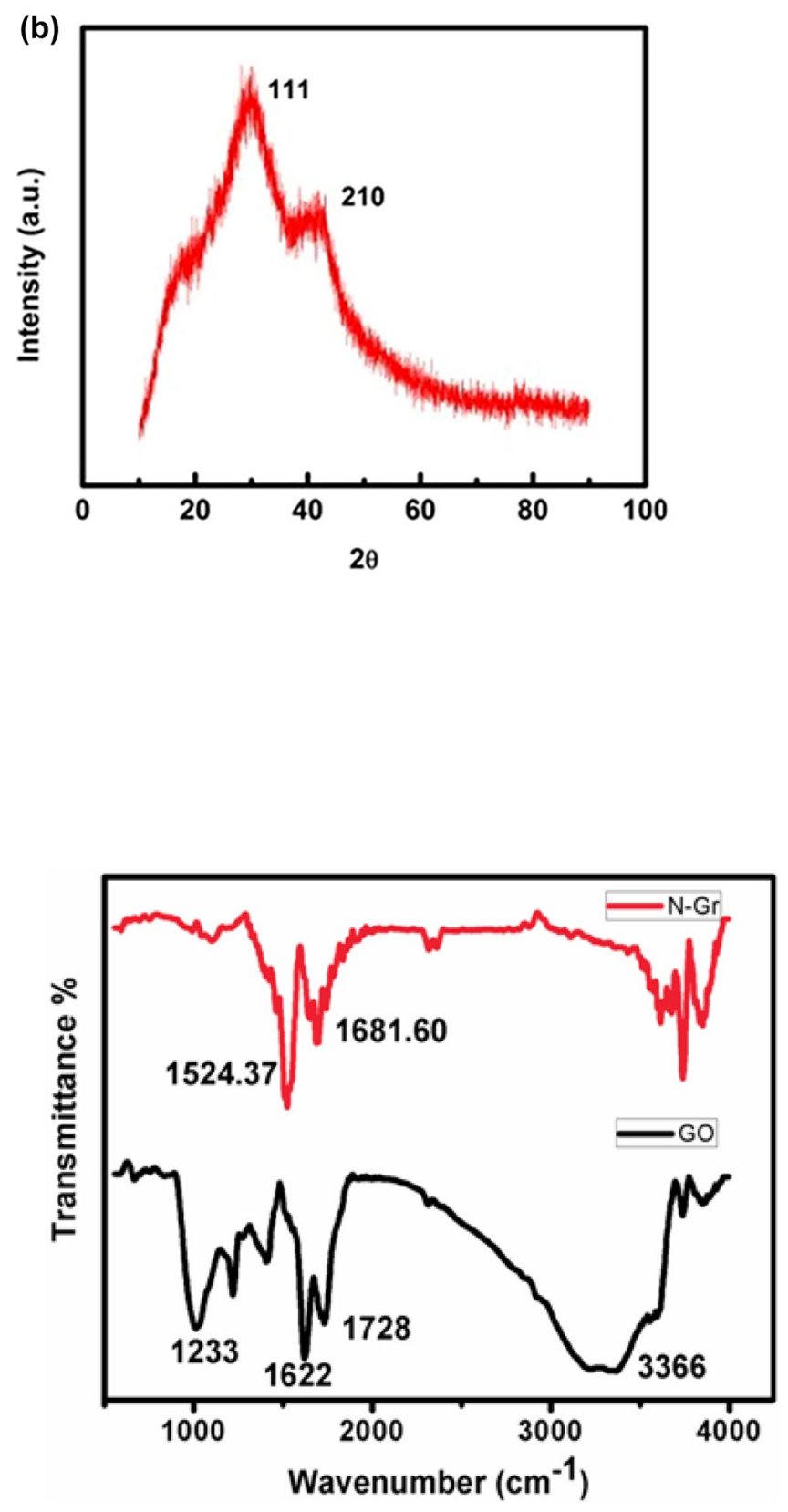

Fig. 3 FTIR spectra of graphene oxide and $\mathrm{NH}_{2}-\mathrm{r}-\mathrm{GO}$ 
1622 and $1233 \mathrm{~cm}^{-1}$ attributed to $\mathrm{N}-\mathrm{H}$ bending and $\mathrm{C}-\mathrm{N}$ stretching. Thus FTIR analysis confirms the amine functionalization of GO followed by reduction to amino-rGO.

FE-SEM images of $\mathrm{NH}_{2}$-rGO composite obtained at different resolutions are depicted in Fig. 4. Typical nano flakes morphology was found in the $\mathrm{NH}_{2}-\mathrm{rGO}$ and some areas of the composites shows an irregular morphology with multiple shapes including sheets. The amino-rGO sheets are informally folded onto each other with many ripples and seem to form tangled patches. A porous network with a size ranging from $300 \mathrm{~nm}$ to $10 \mu \mathrm{m}$ is found between the crosswise edges of the multi-layer of amino-rGO. These specifications could be related to the hydrogen bonding of amino surface functional groups.

Figure 5 a represents DPV of DA $\left(2.04 \times 10^{-3} \mathrm{M}\right)$ at bare GCE and $\mathrm{NH}_{2}-\mathrm{rGO}$ modified GCE in which comparison of DPV reveals significantly enhancement of faradic current at modified electrode and well defined oxidation peak occurred at $0.26 \mathrm{~V}$ similarly in Fig. 5b DPV of UA $\left(1.8 \times 10^{-3} \mathrm{M}\right)$ exhibits poor current response at bare GCE and broad oxidation peak at modified electrode therefore from the experimental results it was shown that $\mathrm{NH}_{2}-\mathrm{rGO}$
Fig. 4 FESEM image of amino $\mathrm{rGO}$ at resolution of a $300 \mathrm{~nm}$, b $2 \mu \mathrm{m}, \mathrm{c} 3 \mu \mathrm{m}, \mathbf{d} 10 \mu \mathrm{m}$
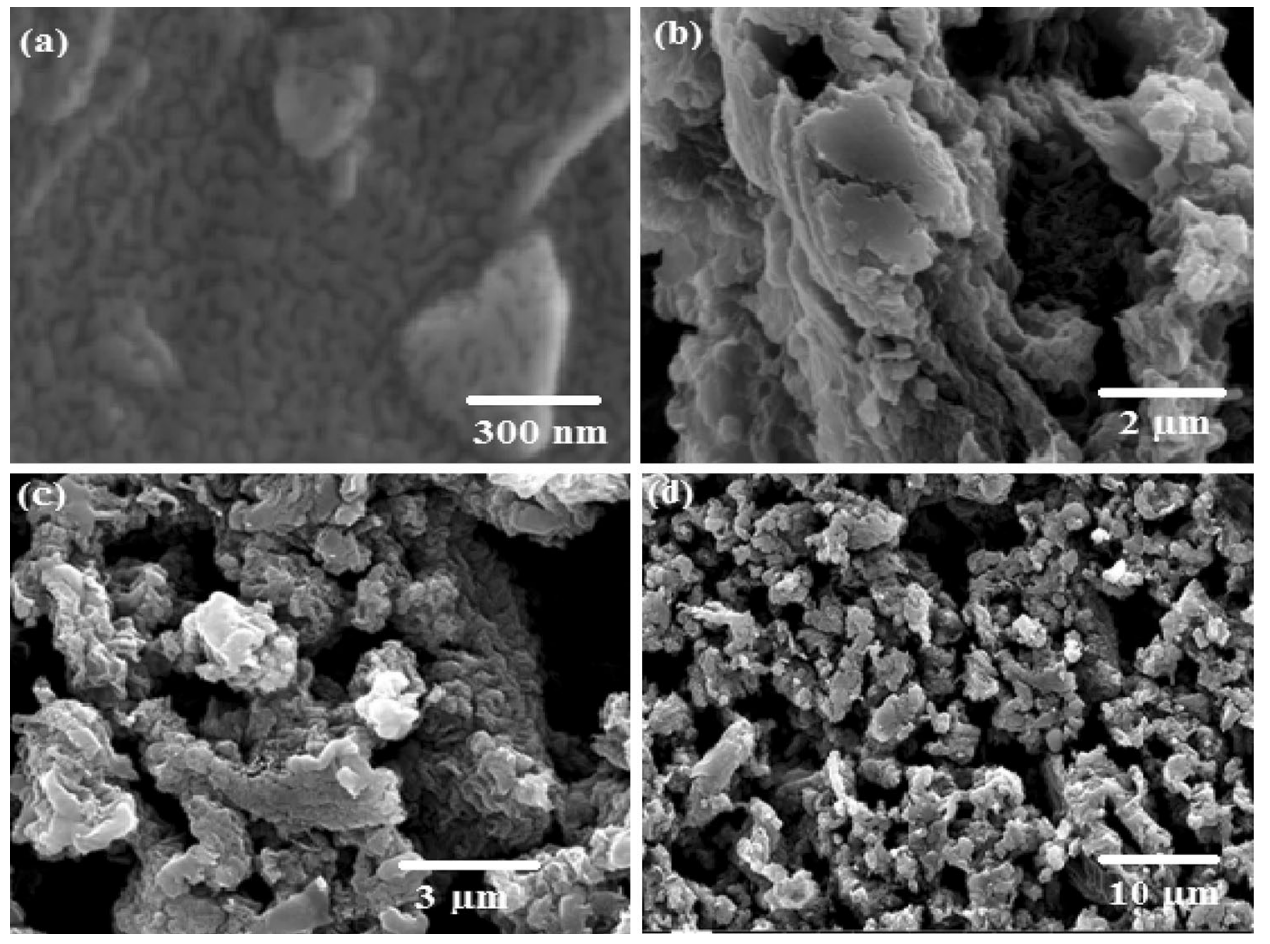

(a)

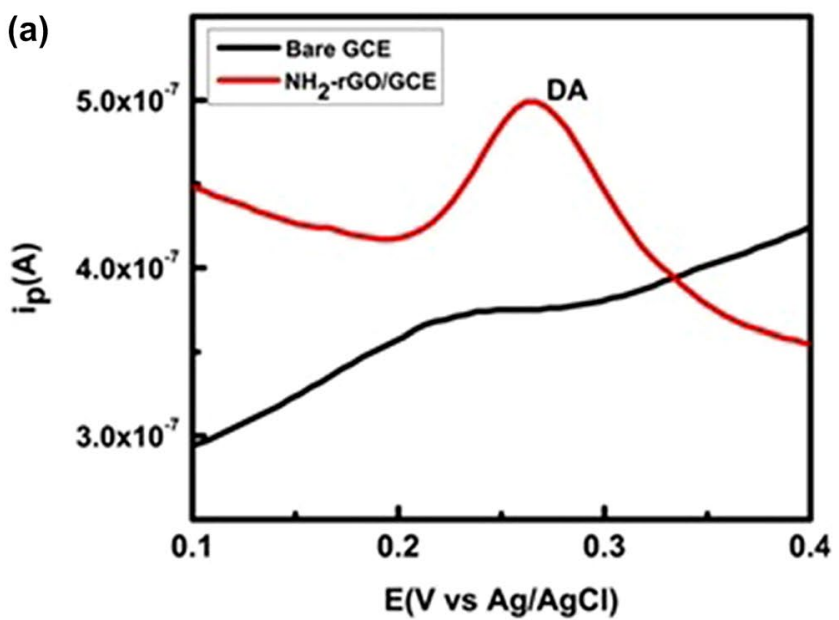

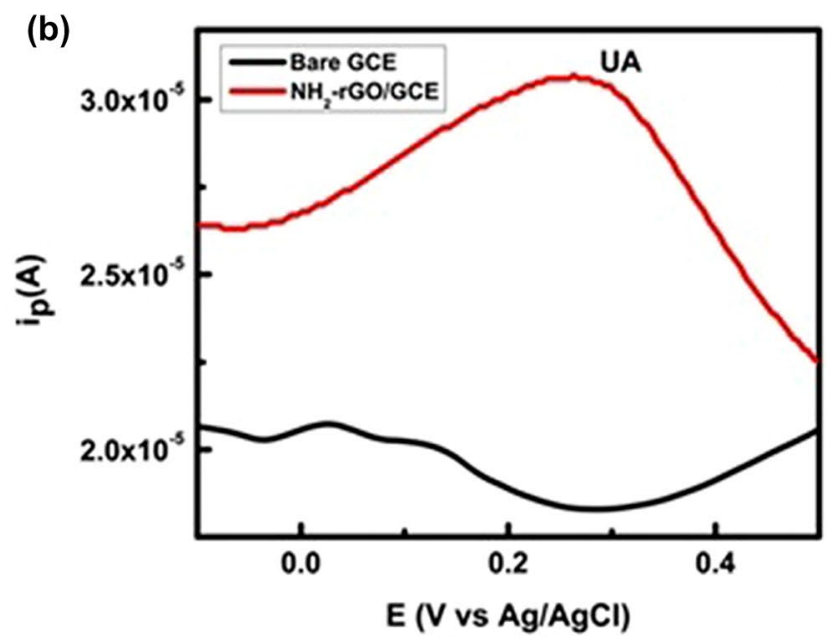

Fig. 5 a DPV of bare GCE and modified $\mathrm{NH}_{2}-\mathrm{rGO} / \mathrm{GCE}$ in $0.1 \mathrm{M}$ acetate buffer ( $\mathrm{pH}$ 3) with DA and UA 
modified electrode exhibits more electro-catalytic behavior toward both analyte DA and UA due to fast electron transfer kinetics and certainly due to increase in the surface area of GCE by modifying $\mathrm{NH}_{2}-\mathrm{rGO}$. Which further leads to electrostatic interaction between $\mathrm{NH}_{2}-\mathrm{rGO}$ and both analyte which results into oxidation of dopamine and uric acid.

Figure 6a shows overlay DPV (Modulated amplitude $0.025 \mathrm{~V}$ step width of $0.005 \mathrm{~V}$ and with the interval time of $0.5 \mathrm{~s}$.) increasing concentrations of $D A$ $\left(2.04 \times 10^{-4}-2.04 \times 10^{-3} \mathrm{M}\right)$ at $\mathrm{NH}_{2}-\mathrm{rGO} / \mathrm{GCE}$ in acetate buffer ( $\mathrm{pH} 3$ ). The DA shows oxidation at $0.26 \mathrm{~V}$ against $\mathrm{Ag} / \mathrm{AgCl}$ reference electrode. With increasing concentration, no shift in the oxidation peak position of DA was observed indicates that the absence of electrode poisoning by adsorption or formation of barrier layer for diffusion of fresh DA molecules to the surface of sensor. Figure $6 \mathrm{~b}$ depicts a plot of oxidation pulse peak current versus concentration of DA at the $\mathrm{NH}_{2}-\mathrm{rGO}$ / GCE shows linear relationship with the regression equation $\left(1.6468 \times 10^{-4} \mathrm{C}+3.680 \times 10^{-7}\right.$ with $\left.\mathrm{R}^{2}=0.99\right)$. The detection limit given by the equation,
$C_{\lim }=\frac{3 \delta}{K}$

where $\delta$ is standard deviation and $k$ represents a slope of calibration graph. The sensitivity of $\mathrm{NH}_{2}-\mathrm{rGO}$ modified GCE for DA are determined using Randles-Sevcik equation [38].

$\mathrm{I}_{\mathrm{pa}}=2.69 \times 10^{5} \mathrm{n}^{3 / 2} \mathrm{D}^{1 / 2} \mathrm{v}^{1 / 2} \mathrm{AC}$

where $I_{p a}$ is oxidation pulse peak current of DA; $n$ is the total number of electrons transferred; $A$ is electrochemical active surface area of working electrode $\left(\mathrm{cm}^{2}\right)$. The sensitivity and LOD were calculated from the calibration plot and found to be $10.294 \mathrm{~A} \mathrm{~L} \mathrm{~mol}^{-1} \mathrm{~cm}^{-2} \mathrm{~A}$ and $1.383 \times 10^{-4} \mathrm{M}$ respectively.

Similarly, Fig. 6c, d represents the overlay DPV and the calibration plot with increasing concentration of UA in the concentration range of $1.8 \times 10^{-3}-1.8 \times 10^{-4} \mathrm{M}$. The DPV shows the oxidation peak of UA at $0.26 \mathrm{~V}$ compared to Fig. $6 \mathrm{a}$, anodic peak of dopamine about $0.19 \mathrm{~V}$ which is sufficiently more positive than the oxidation peak of UA. This indicate the oxidation of DA is energetically more
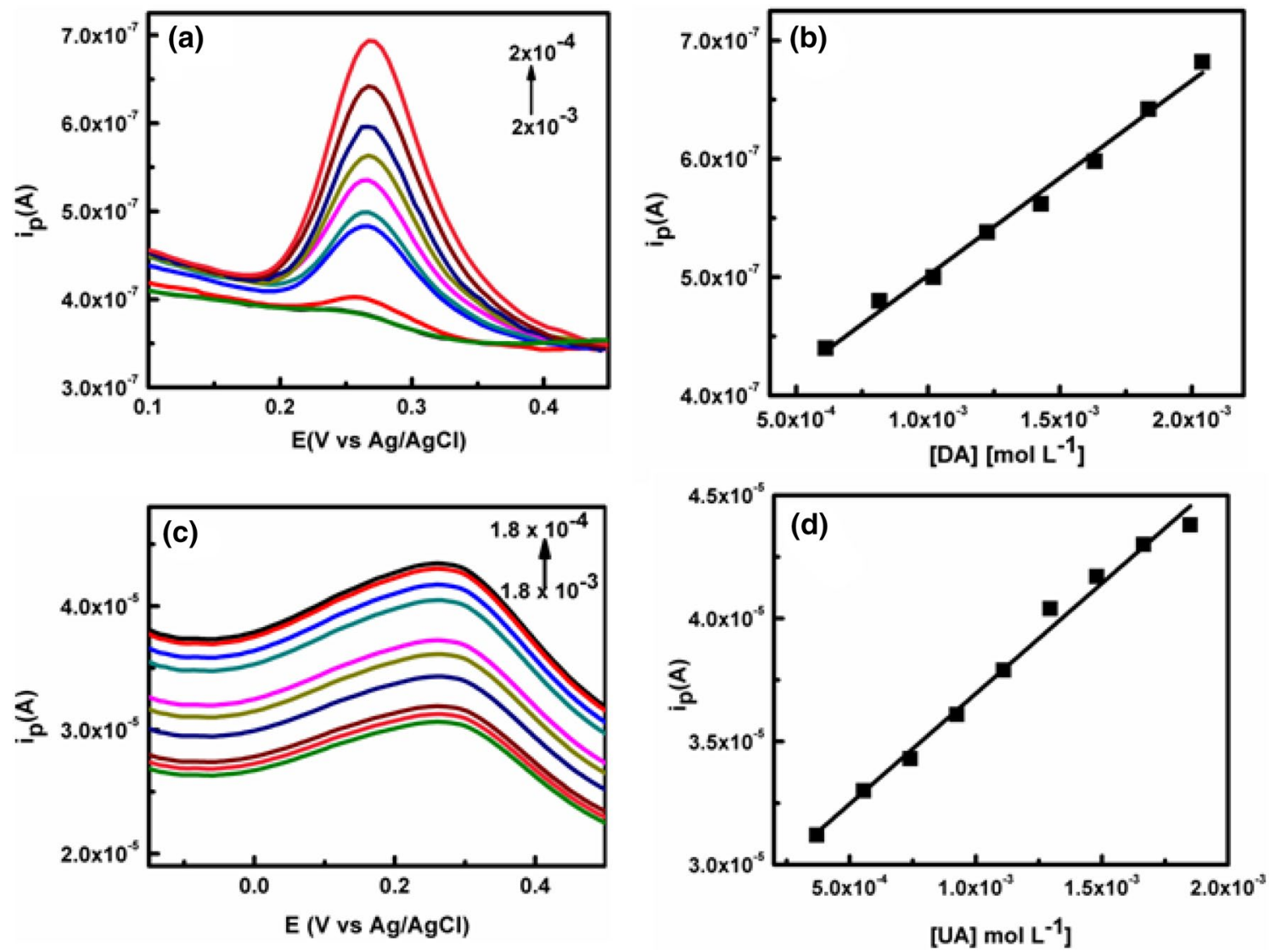

Fig. 6 a DPV of DA at $\mathrm{NH}_{2}-\mathrm{rGO}$ modified GCE in $0.1 \mathrm{M}$ acetate buffer (pH 3), b plot of the pulse peak current versus [DA], c DPV of Glassy carbon modified $\mathrm{NH}_{2}-\mathrm{rGO}$ electrode with increasing concentration of UA in acetate buffer $\mathrm{pH}$ 3. $\mathbf{d}$ Plot of the pulse peak current versus [UA] 
favorable over UA. Also, the overlay DPV of UA shows slight shift in the oxidation peak with increasing concentration of UA indicates that the electrode becomes catalytic for higher concentrations of UA. The wider gap in the oxidation peak potential of DA and UA opens up the possibility of simultaneous detection of these biomolecules at $\mathrm{NH}_{2}-\mathrm{rGO}$ modified GCE. The calibration plot depicted in Fig. $6 \mathrm{~d}$ shows linear behavior with linear regression equations $\mathrm{I}_{\mathrm{pa}}=0.00896 \mathrm{C}+2.798 \times 10^{-5}$, the correlation coefficient for the linearity was $\left(R^{2}=0.98\right)$. The limit of detection found to be $1.67 \times 10^{-4} \mathrm{M}$.

The selectivity of the $\mathrm{NH}_{2}-\mathrm{rGO} / \mathrm{GCE}$ sensor for the simultaneous determination of DA and UA were checked in the presence of high concentration of biologically active interfering compounds. Figure 7 represents DPVs of DA and $U A$ in the presence of interfering biomolecules glucose and $A A$. The peak position and peak current of DA and UA remains same indicates absence of effects of these molecules on the Faradic activity. The separation between the oxidation peaks of UA and DA in DPV were large enough for the simultaneous determination.

\subsection{Simultaneous determination of UA and DA}

Figure 8 depicts DPV of simultaneous investigation of DA and UA using the mixture of $1 \times 10^{-3} \mathrm{M} \mathrm{DA}$ and $9.25 \times 10^{-3} \mathrm{M} \cup A$ in $0.1 \mathrm{M}$ acetate buffer $(\mathrm{pH} 3)$. The modified $\mathrm{NH}_{2}$-rGO/GCE shows enhancement of redox peak current than bare GCE this implies the electro-catalytic activity of $\mathrm{NH}_{2}-\mathrm{rGO} / \mathrm{GCE}$ for DA and UA even in the mixture.

Figure 9a represent the overlay DPVs of the $2 \times 10^{-3} \mathrm{M}$ DA with increasing concentration of UA in the range of $1.24 \times 10^{-5}-6.19 \times 10^{-5} \mathrm{M}$ and Fig. $9 \mathrm{c}$ represent the overlay DPVs of the $1.8 \times 10^{-3} \mathrm{M} \cup \mathrm{A}$ with increasing concentration

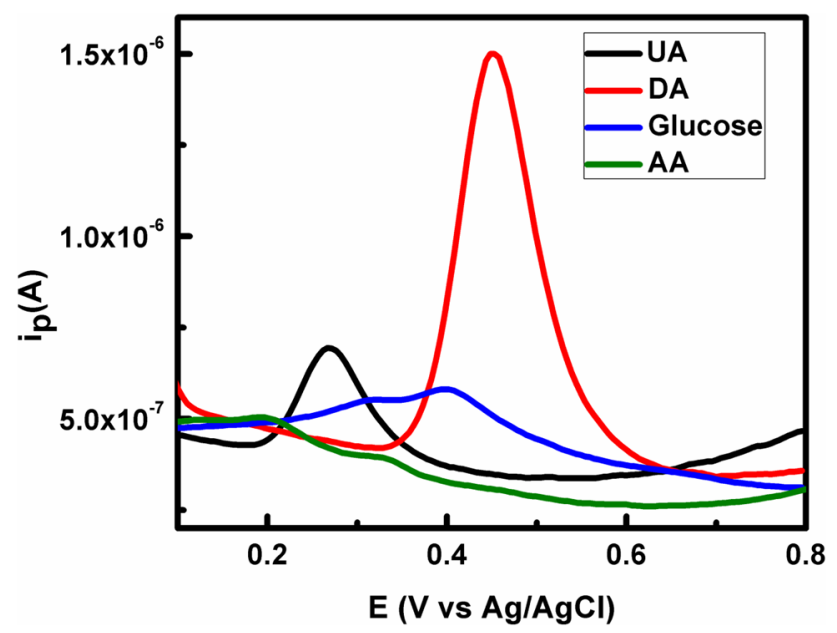

Fig. 7 Interference study at $\mathrm{NH}_{2}-\mathrm{rGO} / \mathrm{GCE}$ with $1 \mathrm{mM}$ DA in the presence of $0.05 \mathrm{M} \mathrm{UA}, \mathrm{DA}$, and glucose in acetate buffer $(\mathrm{pH} 3)$

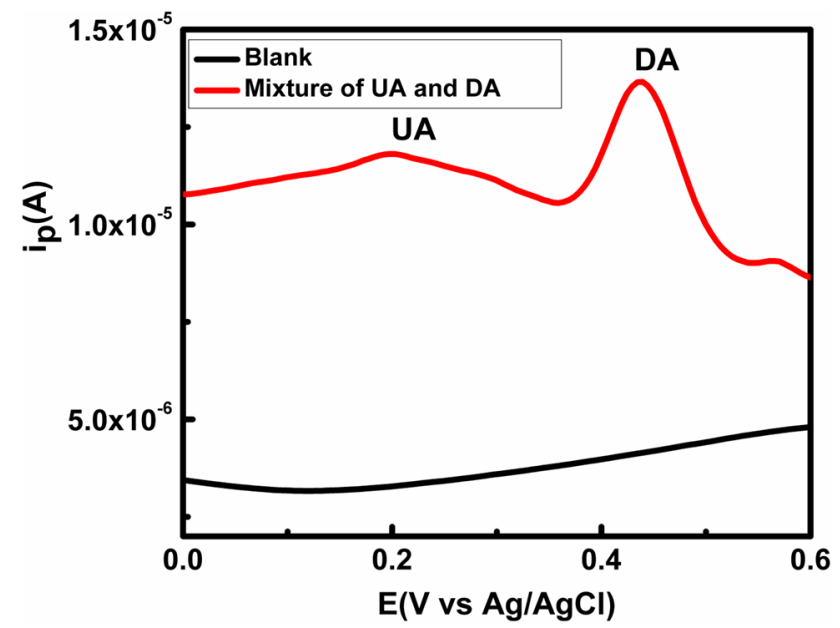

Fig. 8 Differential pulse voltammograms mixture of $1 \times 10^{-3} \mathrm{M}$ DA and $9.25 \times 10^{-4} \mathrm{M} \mathrm{UA}$ in $0.1 \mathrm{M}$ acetate buffer solution of $\mathrm{pH} 3.0$

of $D A$ in the range of $1.36 \times 10^{-5}-6.80 \times 10^{-5} \mathrm{M}$. The peak current in both (Fig. 9a, c) DPV overlay were found to increases with increase in concentration of UA and DA. The calibration plots of anodic pulse peak current $\left(I_{p a}\right)$ versus increasing concentration of DA and UA respectively depicted in Fig. 9b, d respectively. The linear correlation with equations $I_{p a}=0.135 C+8 \times 10^{-6}$ and $I_{\text {pa }}=0.11 C+6 \times 10^{-6}$ with $R^{2}=0.99$ were respectively found in UA and DA. The LOD, LOQ sensitivity found for the individual and binary mixture represented in Table 1. Thus, the modified $\mathrm{NH}_{2}-\mathrm{rGO} / \mathrm{GCE}$ electrode can be used for the simultaneous determination of binary mixture contain DA and UA.

\subsection{Effect of $\mathrm{pH}$ on the redox activity of DA and UA}

Effect of $\mathrm{pH}$ on the oxidation behavior of DA and UA are studied for involvement of protons, which consequently related to the oxidation peak shape and peak potential of the DA and UA. The influence of $\mathrm{pH}$ on the electrochemical behavior of DA (Fig. 10a) was investigated over a $\mathrm{pH}$ range of acidic to basic (3-8), the redox activity of $0.081 \mathrm{M} \mathrm{DA}$ at $\mathrm{NH}_{2}-\mathrm{rGO} / \mathrm{GCE}$ was investigated by DPV. The DA displays a well defined oxidation response at $\mathrm{NH}_{2}-\mathrm{rGO}$ composite for each $\mathrm{pH}$ value. DA shows well defined catalytic current response for $\mathrm{pH} 3$, so we have carried out all investigation at $\mathrm{pH}$ 3. With increasing $\mathrm{pH}$, we found the negative shift in the oxidation peak potential of DA which is attributed to the decreasing barrier for the oxidation of DA in less protic environment. Similarly the oxidation behavior of UA (Fig. 10c) shows the catalytic response at $\mathrm{pH} 3$, for other $\mathrm{pH}$, no redox activity was observed indicates that the UA shows charge transfer only in case of high proton concentration. Both DA and UA showed catalytic response at 

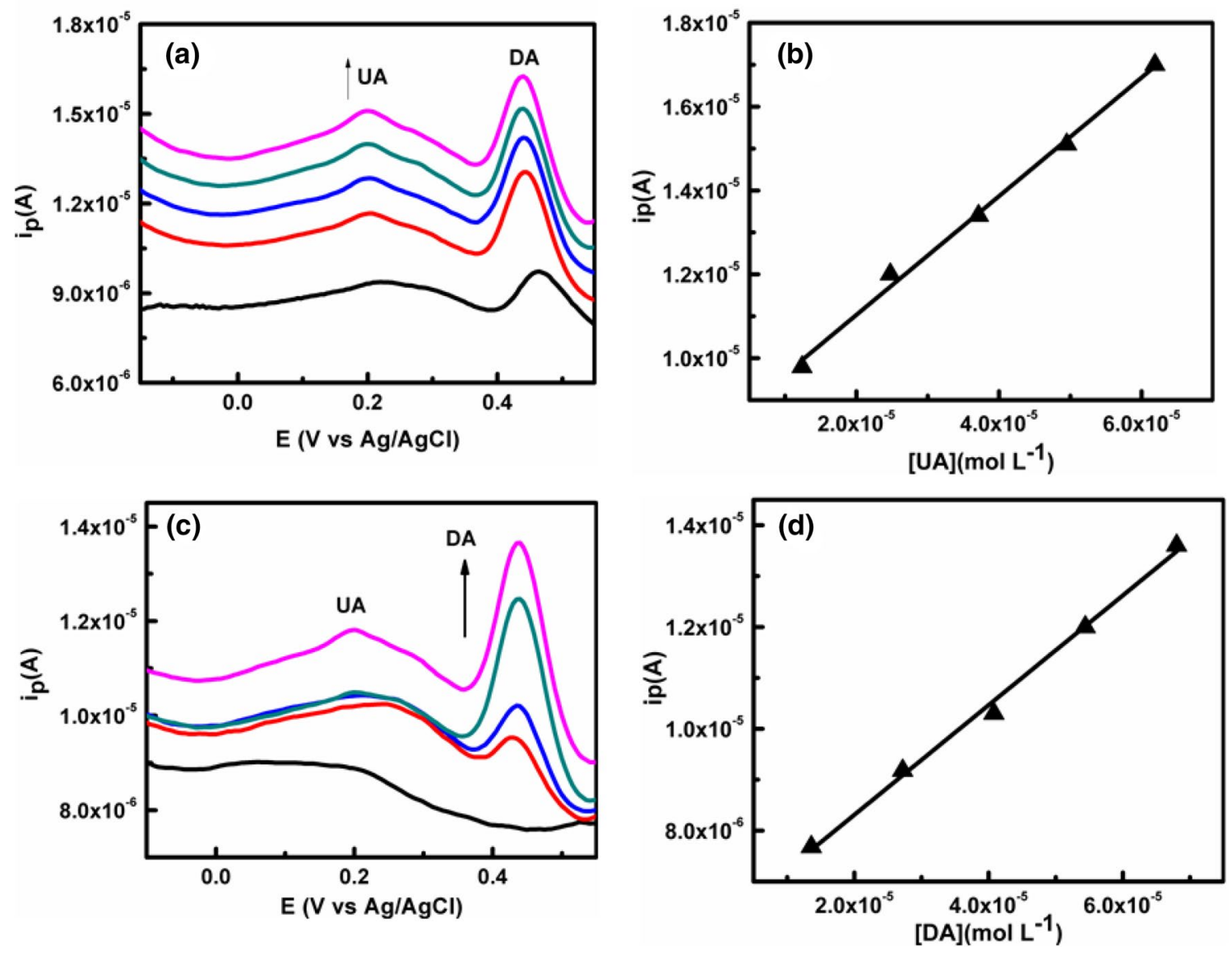

Fig. 9 Overlay DPV of DA and UA at $\mathrm{NH}_{2}-\mathrm{rGO}$ nanocomposite a with increasing concentration of UA at $2 \times 10^{-3} \mathrm{M}$ of DA and $\mathrm{c}$ with increasing concentration of DA at $1.8 \times 10^{-3} \mathrm{M}$. of UA. b, $\mathbf{d}$ The cali-

bration plots for increasing concentration of DA and UA in $0.1 \mathrm{M}$ acetate buffer solution at $\mathrm{pH} 3.0$
Table 1 Electrochemical sensing parameters of $\mathrm{NH}_{2}-$ rGO/GCE for oxidation DA, UA and binary mixture of DA and UA

\begin{tabular}{lllll}
\hline System & LOD (M) & LOQ (M) & $\begin{array}{l}\text { Sensitivity } \\
\left(\mathrm{A} \mathrm{L} \mathrm{mol} \mathrm{cm}^{-1}\right)\end{array}$ & Linear range (M) \\
\hline Individual with increasing [DA] & $1.40 \times 10^{-4}$ & $4.62 \times 10^{-4} \mathrm{M}$ & 10.29 & $2.04 \times 10^{-3}-2.04 \times 10^{-4}$ \\
Individual with increasing [UA] & $1.67 \times 10^{-4}$ & $5.40 \times 10^{-4} \mathrm{M}$ & $3.49 \times 10^{-4}$ & $1.80 \times 10^{-3}-1.80 \times 10^{-4}$ \\
Binaryl with increasing [DA] & $3.84 \times 10^{-6}$ & $1.28 \times 10^{-5} \mathrm{M}$ & 4.32 & $1.36 \times 10^{-5}-6.80 \times 10^{-5}$ \\
Binaryl with increasing [UA] & $5.68 \times 10^{-6}$ & $1.89 \times 10^{-5} \mathrm{M}$ & 5.30 & $1.24 \times 10^{-5}-6.19 \times 10^{-5}$ \\
\hline
\end{tabular}

same $\mathrm{pH}$ and at comparatively different oxidation potential therefore, we have chosen $\mathrm{pH} 3$ for individual and in case of binary investigation of DA and UA. Figure 10b and $d$ represents plot of peak current vs $\mathrm{pH}$ of $\mathrm{DA}$ and UA which illustrates that enhancement of current at $\mathrm{pH} 3$.

Figure 11 exhibit the Nyquist plots of the bare GCE, $\mathrm{NH}_{2}-\mathrm{rGO} / \mathrm{GCE}$. The faradic electrochemical impedance spectroscopic investigations of bare and modified electrode are carried out in presence of $1 \mathrm{mM}$ ferrocene. AC amplitude of $10 \mathrm{mV}$ is applied for system perturbation with the predefined frequency of $10 \mathrm{kHz}$ to $100 \mathrm{mHz}$ from the impedance study we observed the interfacial electron transfer more physible in case of modified electrode as its value of charge transfer resistance was $1.10 \mathrm{k} \Omega$ was lower than the bare electrode $16.2 \mathrm{k} \Omega$. The semicircular part at higher frequency side controls the electron-transfer resistance between electrode and electrolyte, which controls the electron transfer kinetics of the redox probe at the electrode interface. The linear part at low frequencies, correspond to the diffusion process between electrode and electrolyte.

The application of the modified $\mathrm{NH}_{2}-\mathrm{rGO} / \mathrm{GCE}$ was verified with human urine sample. Urine solutions already contained inherent amount of DA and hence directly 

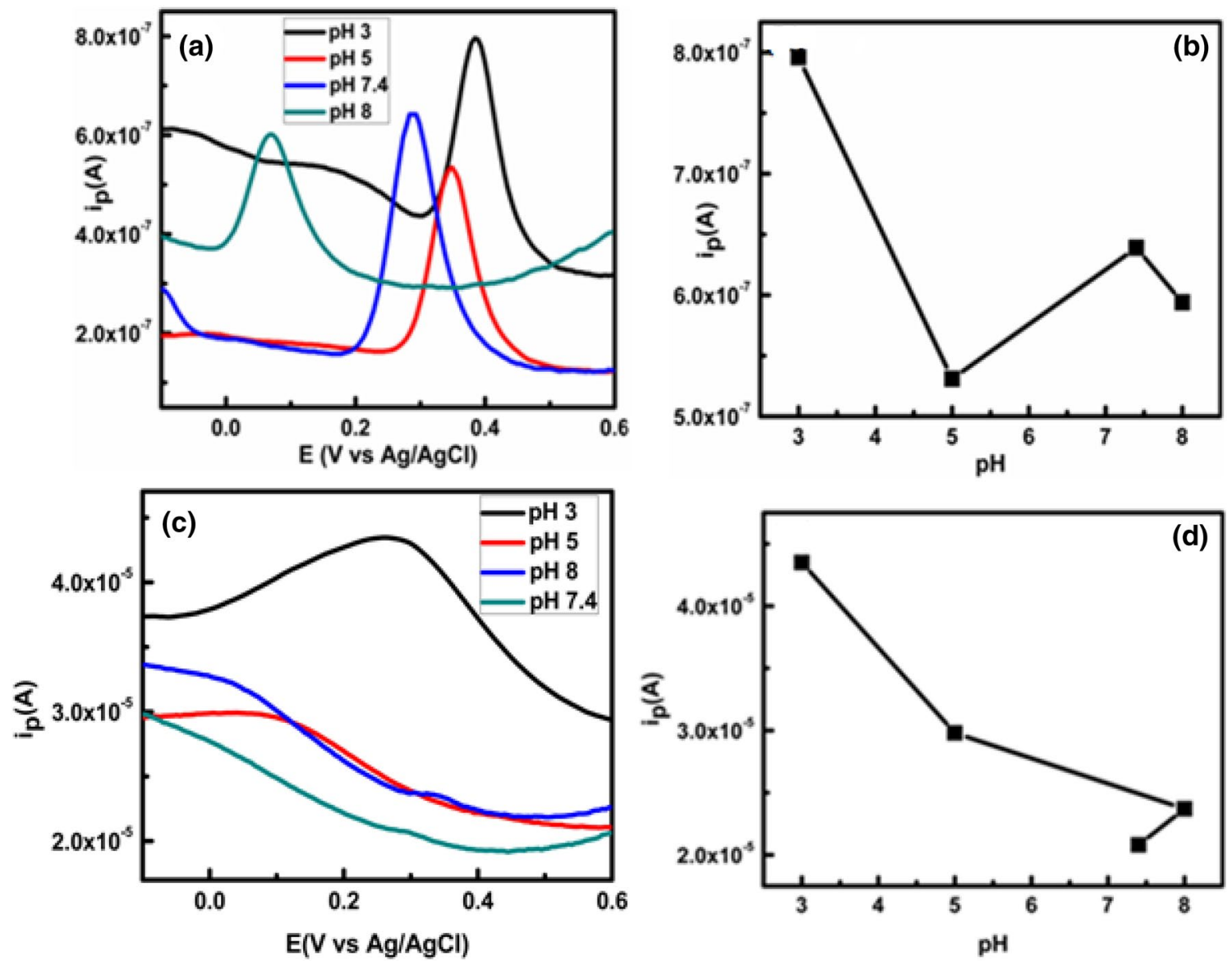

Fig. 10 DPV at the $\mathrm{NH}_{2}-\mathrm{rGO} / \mathrm{GCE}$ in $0.1 \mathrm{M}$ acetate buffer a DA With increasing $\mathrm{pH}$ (3-8), b Peak currents versus pH, $\mathrm{c}$ UA With increasing pH (3-8) in $0.1 \mathrm{M}$ acetate buffer, $\mathbf{d}$ a plot for peak current versus $\mathrm{pH}$

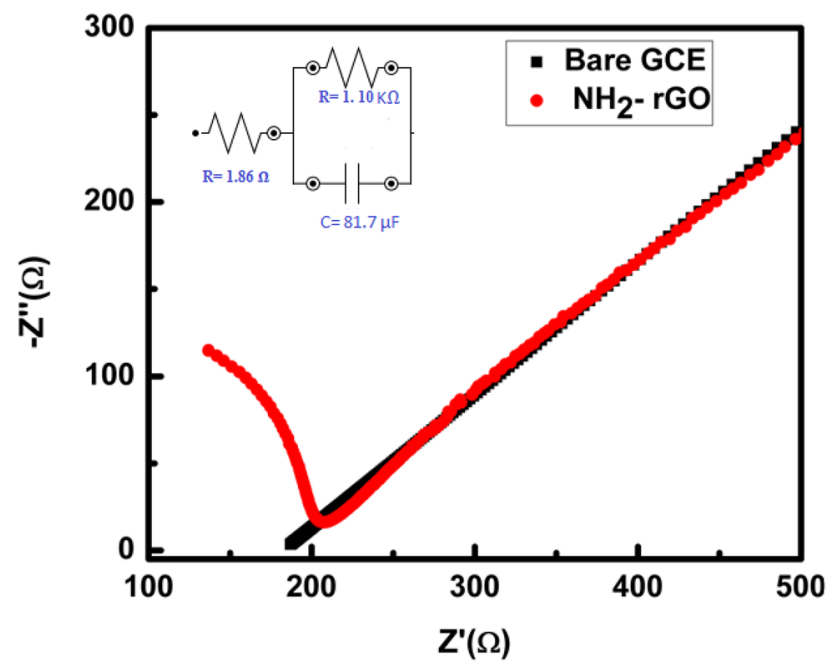

Fig. 11 EIS plots of the bare $\mathrm{GCE}, \mathrm{NH}_{2}-\mathrm{rGO} / \mathrm{GCE}$ in the presence of $1 \mathrm{mmol} \mathrm{L}^{-1}$ ferrocene with $0.1 \mathrm{M} \mathrm{KCl}$ as electrolyte. Inset is the equivalent circuit spiked into the supporting electrolytes. DPV experiments were performed by following the optimized experimental conditions of urine samples. The obtained results of the human urine sample are given in Table 2. From the results, the $\mathrm{NH}_{2}$-rGO/GCE modified electrode revealed the excellent practicality for the determination of DA in human urine samples. The determination values of DA are well consistent with standard values with the RSD of $4.9-2.9 \%$ and the recovery rate is $97.7 \%$. These results indicate that the $\mathrm{NH}_{2}-\mathrm{rGO} / \mathrm{GCE}$ have tremendous application prospects on the sensitive detection of DA in urine sample (Table 3).

\section{Conclusions}

$\mathrm{NH}_{2}$-rGO composite successfully prepared via Bucherer reaction and proved to be an effective, facile, selective and reliable method of synthesis in a single step. The product analysis showed the high percentage of amine groups covalently attached to the reduced graphene oxide and the functionalized reduced graphene oxide sheets with 
Table 2 Comparison for simultaneous determinations of DA and UA at different modified electrode

\begin{tabular}{|c|c|c|c|c|c|}
\hline \multirow[t]{2}{*}{ Electrode } & \multicolumn{2}{|c|}{ Linear range $(\mu \mathrm{M})$} & \multicolumn{2}{|c|}{ Detection limit $(\mu \mathrm{M})$} & \multirow[t]{2}{*}{ References } \\
\hline & DA & UA & DA & UA & \\
\hline Nano CU/PPy/GCE & $0.001-0.1$ & $0.001-0.1$ & 0.00085 & 0.0008 & [39] \\
\hline ZnO NPs/CPE & $0.1-20$ & - & $0-0.03$ & - & {$[40]$} \\
\hline PPy/RGO-GCE & $0.1-150$ & - & 0.023 & - & {$[41]$} \\
\hline ZnO-sG-Nafion & $10-800$ & - & 1.0 & - & {$[42]$} \\
\hline $\mathrm{NiO} / \mathrm{ZnO} / \mathrm{CPE}$ & $6-100$ & $629-6290$ & 1.0 & 1.29 & [43] \\
\hline $\mathrm{NH}_{2}-\mathrm{rGO} / \mathrm{GCE}$ & $\begin{array}{l}2.04 \times 10^{-3}- \\
2.04 \times 10^{-4} \mathrm{M}\end{array}$ & $1.8 \times 10^{-3}-1.8 \times 10^{-4}$ & $0.4 \times 10^{-4} \mathrm{M}$ & $1.67 \times 10^{-4} \mathrm{M}$ & [This work] \\
\hline
\end{tabular}

Table 3 Analysis of DA real samples

\begin{tabular}{lllll}
\hline Sample & Added $(\mu \mathrm{M})$ & Found $(\mu \mathrm{M})$ & \% recovery & $\%$ RSD \\
\hline Sample 1 & 59 & 58 & 98.3 & 2.9 \\
Sample 2 & 35 & 34 & 97.1 & 4.9 \\
\hline
\end{tabular}

amine have a larger layer-to-layer distance. This study reveals that GCE modified by $\mathrm{NH}_{2}-\mathrm{rGO}$ nanocomposite could be utilized for the electrochemical determination of DA and UA individually and simultaneously. This sensor not only showed high electrocatalytic performance, high stability and excellent selectivity toward the electro oxidation of the two biomolecules, but it also presented two sharpened ambiguous oxidation peaks instead of the overlapped anodic peaks. The decoration of $\mathrm{rGO}$ with amine group can provide excellent electrochemical platforms for DA and UA analysis due to the combination of the enlarged active surface area, strong adsorptive capability of the nanomaterials and their specific interactions ability.

Acknowledgements SNT thanks Shivaji University Kolhapur for providing minor research project under Research Strengthening Scheme (SU/C \& U. D. Section/95/1391).

\section{Compliance with ethical standards}

Conflict of interest All authors declares that no conflict of interest exist.

\section{References}

1. Karthik R, Saravanakumar K, Chen S, Vinoyh Kumar J, Lee C, Lou B, Muthuraj V, Elangovan A, Kulandaivel S (2017) Eco-friendly synthesis of gold nanoparticles by using $B$. javanica Blume leaves extract encapsulated with graphene oxide for selective electrochemical detection of dopamine. Int J Electrochem Sci 12:1474-1491. https://doi.org/10.20964/2017.02.61

2. Bergquist J, Sciubisz A, Kaczor A, Silberring J (2002) Catecholamines and methods for their identification and quantitation in biological tissues and fluids. J Neurosci Methods 113:1-13. https ://doi.org/10.1016/S0165-0270(01)00502-7
3. Adekunle A, Agboola B, Pillay J, Ozoemena K (2010) Electrocatalytic detection of dopamine at single-walled carbon nanotubes-iron(III) oxide nanoparticles platform. Sens Actuators B 148:93-102. https://doi.org/10.1016/j.snb.2010.03.088

4. Komathi S, Gopalan A, Lee K (2010) Nanomolar detection of dopamine at multi-walled carbon nanotube grafted silica network/gold nanoparticle functionalised nanocomposite electrodes. Analyst 135:397-404. https://doi.org/10.1039/B918335C

5. Huang S, Liao H, Chen D (2010) Simultaneous determination of norepinephrine, uric acid and ascorbic acid at a screen printed carbon electrode modified with polyacrylic acid-coated multiwall carbon nanotubes. Biosens Bioelectron 25:2351-2355. https://doi.org/10.1016/j.bios.2010.03.028

6. Behera S, Raj C (2007) The have been reports on the electrochemical detections of DA and UA both by individual and by simultaneous detections. Mercaptoethylpyrazine promoted electrochemistry of redox protein and amperometric biosensing of UA. Biosens Bioelectron 23:556-561. https://doi. org/10.1016/j.bios.2007.06.012

7. Hass B, Stewart T, Zhang J (2012) Premotor biomarkers for Parkinson's disease: a promising direction of research. Transl Neurodegener 1:1-11. https://doi.org/10.1186/2047-9158-1-11

8. Chen J, Yan X, Meng K, Wang S (2011) Graphene oxide based photoinduced charge transfer label-free near-infrared fluorescent biosensor for dopamine. Anal Chem 83:8787-8793. https ://doi.org/10.1021/ac2023537

9. Carrera V, Sabater E, Vilanova E, Sogorb M (2007) A simple and rapid HPLC-MS method for simultaneous determination of epinephrine, norepinephrine, dopamine and 5- hydroxytryptamine: application to the secretion of bovine chromaffin cell cultures. J Chromatogr B 847:88-94. https://doi. org/10.1016/j.jchromb.2006.09.032

10. Hong $\mathrm{H}$, Huang $\mathrm{H}$ (2003) Flow injection analysis of uric acid with a uricase and horseradish peroxidase-coupled Sepharose column based luminol chemiluminescence system. Anal Chim Acta 499:41-46. https://doi.org/10.1016/S0003-2670(03)00950-4

11. Abbaspour A, Khajehzadeh A, Ghaffarinejad A (2009) A simple and cost-effective method, as an appropriate alternative for visible spectrophotometry: development of a dopamine biosensor. Analyst 134:1692-1698. https://doi.org/10.1039/B901273G

12. Mazloum M, Dehghani A, Benvidi A, Mirjalili B, Mirhoseini M (2014) Characterization of new molecular self-assembled monolayers on gold electrode by QCM, EIS, SEM and CV techniques: application for electrocatalytic determination of dopamine in the presence of acetaminophen. J Iran Chem Soc 12:677-685. https://doi.org/10.1007/s13738-014-0526-3

13. Zhang Y, Yuan R, Chai Y, Zhong X, Zhong H (2012) Carbon nanotubes incorporated with sol-gel derived $\mathrm{La}(\mathrm{OH})_{3}$ nanorods as platform to determine simultaneously ascorbic acid, dopamine, uric acid and nitrite. Colloids Surf B Biointerfaces 100:185-189. https://doi.org/10.1016/j.colsurfb.2012.04.044 
14. Mazloum $M$, Naser $A$, Sheikh M, Benvidi A, Naeimi H, Karshenas A (2013) An electrochemical sensor based on carbon nanotubes and a new Schiff base for selective determination of dopamine in the presence of uric acid, folic acid, and acetaminophen. Ionics 19:1663-1671. https://doi.org/10.1007/s11581-013-0879-0

15. Ghanbari K, Hajheidari N (2015) ZnO- $\mathrm{Cu}_{\mathrm{x}} \mathrm{O} /$ Polypyrrole nanocomposite modified electrode for simultaneous determination of ascorbic acid, dopamine and uric acid. Anal Biochem 473:53-62. https://doi.org/10.1016/j.ab.2014.12.013

16. Sheikhmohseni M, Beitollahi H, Benvidi A, Naeimi H (2011) Simultaneous determination of dopamine, uric acid, and folic acid by a modified $\mathrm{TiO}_{2}$ nanoparticles carbon paste electrode. Turk J Chem 35:573-585. https://doi.org/10.3906/kim-1007-784

17. Yang L, Liu S, Zhang Q, Li F (2012) Simultaneous electrochemical determination of dopamine and ascorbic acid using AuNPs @ polyaniline core-shell nanocomposites modified electrode. Talanta 89:136-141. https://doi.org/10.1016/j.talanta.2011.12.002

18. Reddy Y, Rao V, Reddy A, Lavanya M, Venu M, Madhavi G (2015) Determination of dopamine in presence of ascorbic acid and uric acid using poly (Spands Reagent) modified carbon paste electrode. Mater Sci Eng C 57:378-386. https://doi.org/10.1016/j. msec.2015.08.005

19. Tezerjani M, Benvidi A, Dehghani A, Mazloum M, Akbari A (2017) Epinephrine electrochemical sensor based on a carbon paste electrode modified with hydroquinone derivative and graphene oxide nano-sheets: simultaneous determination of epinephrine, acetaminophen and dopamine. Measurement 101:183-189. https ://doi.org/10.1016/j.measurement.2017.01.029

20. Wang B, Luo B, Liang M, Wang A, Wang J, Fang Y, Chang Y, Zhi L (2011) Chemical amination of graphene oxides and their extraordinary properties in the detection of lead ions. Nanoscale 3:50595066. https://doi.org/10.1039/C1NR10901D

21. Mutyala S, Mathiyarasu J (2016) A reagentless non-enzymatic hydrogen peroxide sensor presented using electrochemically reduced graphene oxide modified glassy carbon electrode. Mater Sci Eng C 69:398-406. https://doi.org/10.1016/j.msec.2016.06.069

22. Gao X, Jang J, Nagas J (2010) Hydrazine and thermal reduction of graphene oxide: reaction mechanisms, product structures and reaction design. J Phys Chem C 114:832-842. https://doi. org/10.1021/jp909284g

23. Reddy Y, Sravani B, Maseed H, Łuczak T, Osińska M, SubramanyamSarma L, Srikanth VV, Madhavi G (2018) Ultrafine Pt-Ni bimetallic nanoparticles anchored on reduced graphene oxide nanocomposites for boosting electrochemical detection of dopamine in biological samples. New J Chem 42:16891-16901. https://doi. org/10.1039/C8NJ03894E

24. Benvidi A, Dalirnasab S, Jahanbani S, Tezerjani M, Ardakani M, Mirjalili B, Zare R (2016) Development of a carbon paste electrode modified with reduced graphene oxide and an imidazole derivative for simultaneous determination of biological species of N-acetyl-L-cysteine, uric acid and dopamine. Electroanalysis 28:1625-1633. https://doi.org/10.1002/elan.201501076

25. Reddy Y, Bathinapatla S, Łuczak T, Osińska M, Maseed H, Ragavendra P, Sarma L, Srikanth V, Madhavi G (2018) An ultra-sensitive electrochemical sensor for the detection of acetaminophen in the presence of etilefrine using bimetallic $\mathrm{Pd}-\mathrm{Ag} /$ reduced graphene oxide nanocomposites. New J Chem 42:3137-3146. https://doi. org/10.1039/C7NJ04775D

26. Bucherer H, Prakt J (1904) Bucherer carbazole synthesis. J Prakt Chem 69:49-91. https://doi.org/10.1002/anie.196703071

27. Chen C, Zhang Q, Zhao X, Zhang B, Kong Q, Yang M, Yang Q, Wang M, Yang Y, Schlogl R, Su D (2012) Hierarchically aminated graphene honeycombs for electrochemical capacitive energy storage. J Mater Chem 22:14076-14084. https://doi.org/10.1039/C2JM3 $1426 \mathrm{~F}$
28. Sravani B, Raghavendra P, Chandrasekhar Y, Reddy Y, Sivasubramanian R, Venkateswarlu K, Madhavi G, Sarma L (2020) Immobilization of platinum-cobalt and platinum-nickel bimetallic nanoparticles on pomegranate peel extract-treated reduced graphene oxide as electrocatalysts for oxygen reduction reaction. Int J Hydrogen Energy 45:7680-7690. https://doi.org/10.1016/j.jjhyd ene.2019.02.204

29. Venu M, Venkateswarlu S, Reddy Y, Seshadri Reddy A, Gupta $V_{\text {, }}$ Yoon M, Madhavi G (2018) Highly sensitive electrochemical sensor for anticancer drug by a zirconia nanoparticle-decorated reduced graphene oxide nanocomposite. ACS Omega 3:14597-14605. https://doi.org/10.1021/acsomega.8b02129

30. Reddy Y, Sravani B, Agarwal S, Gupta V, Madhavi G (2018) Electrochemical sensor for detection of uric acid in the presence of ascorbic acid and dopamine using the poly(DPA)/SiO $\mathrm{S}_{2} @ \mathrm{Fe}_{3} \mathrm{O}_{4}$ modified carbon paste electrode. J Electroanal Chem 820:168-175. https:// doi.org/10.1016/j.jelechem.2018.04.059

31. Yuan C, Chen W, Yan L (2012) Amino-grafted graphene as a stable and metal-free solid basic catalyst. J Mater Chem 22:7456-7460. https://doi.org/10.1039/C2JM30442B

32. Tetsuka H, Asahi R, Nagoya A, Okamoto K, Tajima I, Ohta R, Okamoto A (2012) Optically tunable amino-functionalized graphene quantum dots. Adv Mater 24:5333-5338. https://doi.org/10.1002/ adma.201201930

33. Kumar G, Roy R, Ghorai U, Thapa R, Mazumder N, Saha S, Chattopadhyay K (2014) Amino-functionalized graphene quantum dots: origin of tunable heterogeneous photoluminescence. Nanoscale 6:3384-3391. https://doi.org/10.1039/C3NR05376H

34. Ramanathan T, Fisher F, Ruoff R, Brinson L (2005) Amino-functionalized carbon nanotubes for binding to polymers and biological systems. Chem Mater 17:1290-1295. https://doi.org/10.1021/ $\mathrm{cm} 048357 f$

35. Marcano D, Kosynkin D, Berlin J, Sinitskii A, Sun Z, Slesarev A, Lawrence B, Lu W, Tour M (2010) Improved synthesis of graphene oxide. ACS Nano 24:4806-4814. https://doi.org/10.1021/nn100 6368

36. Wang G, Yang J, Park J, Guo X, Wang B, Liu H, Yao J (2008) Facile synthesis and characterization of graphene nanosheets. J Phys Chem C 112:8192-8195. https://doi.org/10.1021/jp710931h

37. Hummers W, Offeman R (1998) Preparation of graphitic oxide. J Am Chem Soc 80:1339. https://doi.org/10.1021/ja01539a017

38. Bard A, Faulkner L (2001) Fundamentals and application. Electrochem Methods 2:482

39. Ulubay S, Dursun Z (2010) Cu nanoparticles incorporated polypyrrole modified GCE for sensitive simultaneous determination of dopamine and uric acid. Talant 80:1461-1466. https://doi. org/10.1016/j.talanta.2009.09.054

40. Reddy S, Swamy B, Aruna S, Kumar M, Shashanka R, Jayadevappa $\mathrm{H}$ (2012) Preparation of NiO/ZnO hybrid nanoparticles for electrochemical sensing of dopamine and uric acid. Chem Sens 2:1-8

41. Peng S, Chen H, Kannan P, Kim D (2011) Selective and sensitive determination of dopamine by composites of polypyrrole and graphene modified electrodes. Analyst 136:5134-5138. https:// doi.org/10.1039/C1AN15772H

42. Nayak P, Santhosh P, Ramaprabhu S (2013) Electrochemical sensor for dopamine based on $\mathrm{ZnO}$ decorated graphene nanosheets as the transducer matrix. Graphene 1:25-30. https://doi.org/10.1166/ graph.2013.1009

43. Reddy S, Swamy B, Chandrashekar B, Chitravathi S, Jayadevappa $\mathrm{H}$ (2012) Cationic surfactants-assisted synthesis of ZnO nanoparticles and their modified carbon paste electrode for electrochemical investigation of dopamine. Bioanal Electrochem 4:186-196

Publisher's Note Springer Nature remains neutral with regard to jurisdictional claims in published maps and institutional affiliations. 